
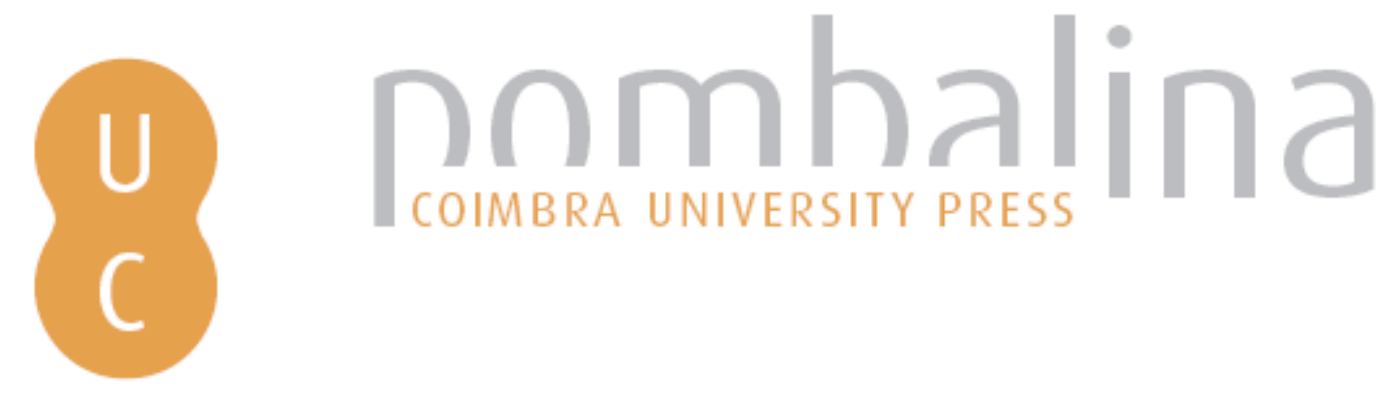

\title{
A pegada jornalística na paisagem mediática
}
Autor(es):
Figueira, João

Publicado por: Imprensa da Universidade de Coimbra

URL

persistente:

URI:http://hdl.handle.net/10316.2/30735

DOI:

DOI:http://dx.doi.org/10.14195/978-989-26-0574-6_11

Accessed : $\quad$ 26-Apr-2023 10:30:15

A navegação consulta e descarregamento dos títulos inseridos nas Bibliotecas Digitais UC Digitalis, UC Pombalina e UC Impactum, pressupõem a aceitação plena e sem reservas dos Termos e Condições de Uso destas Bibliotecas Digitais, disponíveis em https://digitalis.uc.pt/pt-pt/termos.

Conforme exposto nos referidos Termos e Condições de Uso, o descarregamento de títulos de acesso restrito requer uma licença válida de autorização devendo o utilizador aceder ao(s) documento(s) a partir de um endereço de IP da instituição detentora da supramencionada licença.

Ao utilizador é apenas permitido o descarregamento para uso pessoal, pelo que o emprego do(s) título(s) descarregado(s) para outro fim, designadamente comercial, carece de autorização do respetivo autor ou editor da obra.

Na medida em que todas as obras da UC Digitalis se encontram protegidas pelo Código do Direito de Autor e Direitos Conexos e demais legislação aplicável, toda a cópia, parcial ou total, deste documento, nos casos em que é legalmente admitida, deverá conter ou fazer-se acompanhar por este aviso.

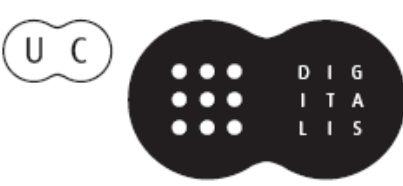




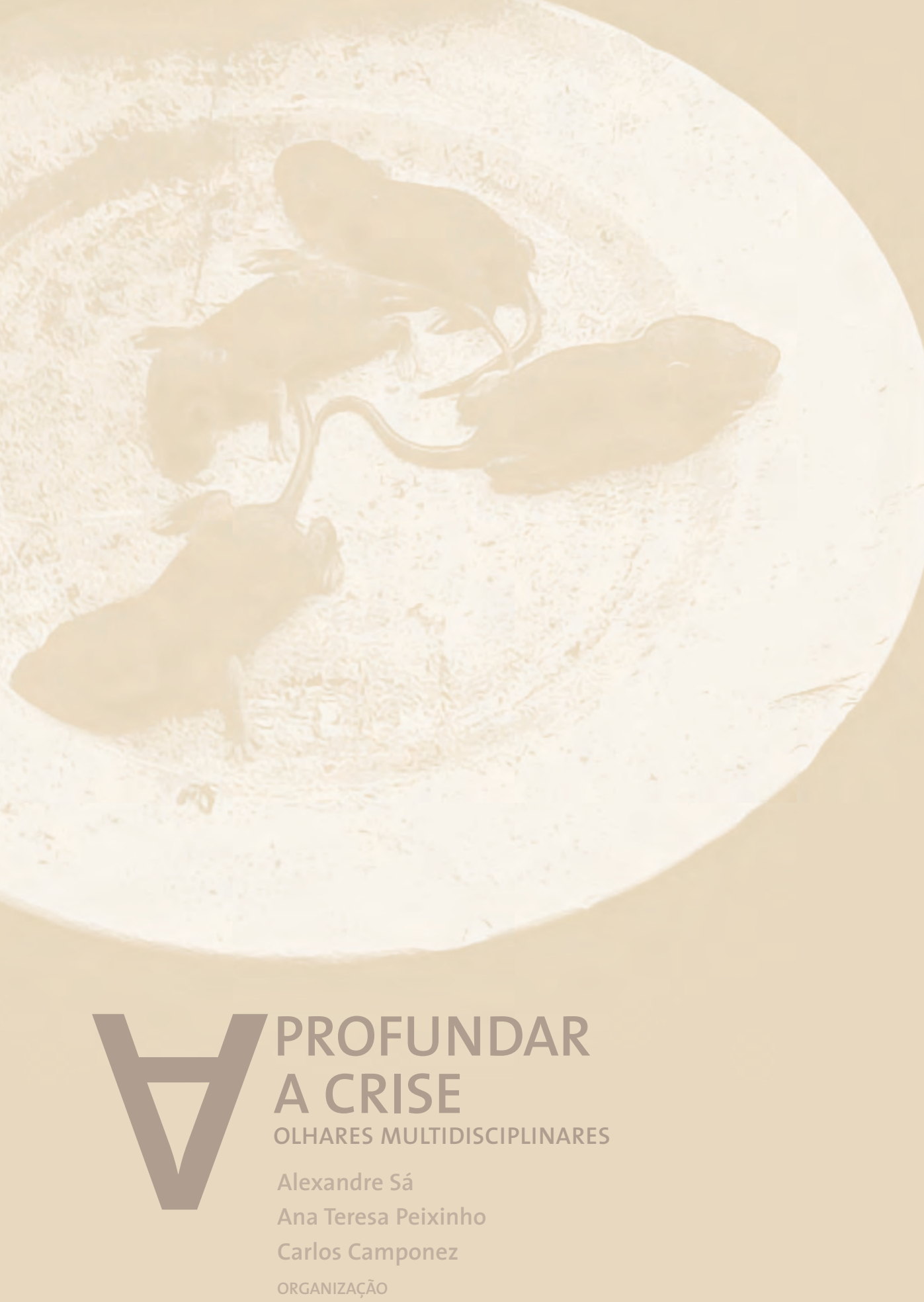


João Figueira

FLUC - CEIS20

\section{A pegada jornalística na paisagem mediática}

"Os media só vão atrás dos carros oficiais". A frase é do jornalista norte-americano, Danny Schechter, que a empregou para questionar o que considera ser o comportamento dominante dos jornalistas. O valenciano Pascual Serrano recupera o conceito, para o aplicar a situações concretas. Diz ele que em março de 2007, enquanto os jornalistas recolhiam diligentemente as frases que George W. Bush fazia na Guatemala, sobre as vantagens do comércio livre no aumento das oportunidades de emprego e no combate à pobreza, ninguém se referiu à unidade de processamento alimentar situada a uma dúzia de quilómetros, e na qual trabalhavam em condições deploráveis menores de 13 anos (Serrano, 2009: 64).

Por essa altura, relembra o mesmo jornalista e especialista em análise dos media, decorria na cidade colombiana de Cartagena das Índias o congresso de língua espanhola, repleto de académicos e líderes políticos. Uma vez mais, assinala Pascual Serrano, os jornalistas estavam demasiado concentrados nas declarações de cada protagonista, ignorando que a escassas centenas de metros do luxuoso hotel onde decorria o congresso, havia um bairro miserável chamado Nelson Mandela, com meio milhão de pobres e um turismo sexual galopante (Serrano, 2009: 64).

Estes dois exemplos revelam o comportamento dominante dos media noticiosos, os quais se pautam, ainda, por uma inexplicável falta de memória. Os detentores de altos cargos políticos sabem que as suas promessas e declarações em cimeiras ou reuniões importantes são sempre objeto de notícia e destaque, sem que os mesmos órgãos de comunicação social se preocupem, seis meses mais tarde, em confirmar se as promessas e os anúncios feitos foram cumpridos. Quer isto dizer, portanto, que, nestes casos, os media noticiosos não nos informam acerca 
do que realmente sucede, mas sobre o que os autores das palavras dizem que vai suceder, porque a atenção informativa está centrada nas declarações de intenção, sem atender às respetivas condições de realização. Ou seja, a informação assim praticada, limita-se às palavras sem depois verificar a sua concretização.

Os casos citados, que como é sabido confirmam a regra de atuação dos media, recentram o debate sobre a informação jornalística nestes tempos de mudança e também de crise, em torno das seguintes questões:

- qual a finalidade do jornalismo e como acrescentar valor à informação jornalística num contexto de perda do monopólio de distribuição da informação?;

- quais os contextos organizacional e comunicacional em que a profissão é exercida?;

- qual o papel dos cidadãos na qualidade da informação fornecida?.

Como veremos, as questões enunciadas relacionam-se entre si numa espécie de vasos comunicantes, porque nenhuma delas existe isolada do conjunto e este é, em grande medida, o resultado da atuação individual de cada uma delas. Por outro lado, esta é, ainda, uma questão crucial do nosso tempo, porquanto, como Dominique Wolton, Manuel Castells ou Furio Colombo oportunamente observaram, todas as sociedades apresentam modelos de comunicação específicos e dominantes, os quais, por sua vez, determinam e influenciam os respetivos modelos informacionais. "Se construímos modelos comunicacionais nas nossas sociedades é também verdade que os principais paradigmas comunicacionais formatam o que um determinado sistema de media será"123.

Ora, nunca como agora, os dois modelos suscitaram tanta reflexão e debate, fruto do seu relacionamento nem sempre fácil e pacífico e, por isso mesmo, gerador de um clima que nos apresenta desafios e problemas.

"O modelo comunicacional da nossa sociedade contemporânea — segundo Gustavo Cardoso - é moldado pela capacidade dos processos de globalização comunicacional mundiais, juntamente com a ligação em rede entre media de massa e media interpessoais e, em consequência, pelo aparecimento da mediação em rede". ${ }^{124}$

123 "Da comunicação de massa para a comunicação em rede", in Media, Redes e Comunicação, (Coord) Gustavo Cardoso, Francisco R. Cádima, Luís L. Cardoso, Quimera, 2009, Lisboa, p. 16

124 "Da comunicação de massa para a comunicação em rede", in Media, Redes e Comunicação, (Coord) Gustavo Cardoso, Francisco R. Cádima, Luís L. Cardoso, Quimera, 2009, Lisboa, p. 16 
O seu ponto de vista, estribado no pensamento de Castells sobre a comunicação em rede, aponta para a afirmação de um novo paradigma "caracterizado pela fusão da comunicação interpessoal e em massa, ligando audiências, emissores e editores sob uma matriz de media em rede"125. Ou seja, coloca os utilizadores e as literacias de que estes necessitam no centro do processo comunicacional. Para Gustavo Cardoso, "o ideal da pessoa informada neste início de século é alguém que sabe produzir conhecimento a partir de todas as notícias disponíveis em diferentes media, com diferentes profundidades de análise e que as pode, e sabe, cruzar com análises mais extensas sobre diferentes assuntos"126. Sem nunca esquecer que na sociedade em rede na qual ele se situa, é a comunicação em rede que predomina e, nesse sentido, aponta para uma valorização da busca de informação no interior desse universo e da sua troca entre os diversos membros das respetivas redes sociais.

Tal pensamento traz consigo a ideia de uma mudança cultural no que toca ao conceito que se faz sobre o que é ser um cidadão informado, muito especialmente no que toca aos processos de troca e acesso à informação, na linha, aliás, do que o investigador norte-americano especialista em economia dos media, Robert Picard defende, quando centra a sua análise e olhar nos aspetos vincadamente económicos do processo informativo. Dentro desse quadro, a informação nem sempre é o bem público, na perspetiva que Bill Kovach e Tom Rosenstiel apontam, quando dizem que "a finalidade do jornalismo não é definida pela tecnologia nem pelos jornalistas ou pelas técnicas que estes empregam, mas pela função que as notícias desempenham na vida das pessoas" (Kovach ; Rosenstiel, 2004: 15). Porque, entendem os mesmos autores, "a principal finalidade do jornalismo é fornecer aos cidadãos a informação de que precisam para serem livres e se autogovernarem" (Kovach ; Rosenstiel, 2004: 16). Nesta perspetiva, o jornalismo "é um saber prudencial que consiste na comunicação adequada do saber sobre as realidades humanas atuais que aos cidadãos é útil saberem para agirem livre e solidariamente" (López, 2001: 258).

O problema, digamos assim, é que atualmente os jornalistas e as empresas para as quais trabalham têm hoje um controle menor sobre os fluxos informativos

\footnotetext{
125 Idem, p. 17

126 Idem, p. 20
} 
e a sua distribuição. De acordo com Robert Picard, as mudanças sociais, económicas e tecnológicas reduziram o papel desempenhado pelos jornalistas e empresas de comunicação social nas sociedades modernas atuais, em que existem mecanismos alternativos que permitem ao público obter, criar e distribuir notícias e informação.

Na conferência que deu no Instituto Reuters para o estudo do Jornalismo, na Universidade de Oxford, a 6 de maio de 2009, sob o título, "Why journalists deserve low paid" e cujas linhas de força e reflexão aprofundou no seu mais recente livro, Value creation and the future of news organizations: why and how journalism must change to remain relevant in the twenty-first century, onde discorre sobre as mudanças que o jornalismo e as empresas de comunicação social têm necessariamente de fazer no contexto de um novo quadro comunicacional determinado pela nova paisagem mediática e de mercado, Robert Picard entende que hoje os produtores de informação noticiosa não têm o poder centralizador e dominador do passado, porquanto agora existe uma ampla rede de fontes capazes de responder, por eles e como eles, às funções e benefícios que, do seu ponto de vista, cabe ao jornalismo desempenhar.

Partindo da ideia de criação de valor inspirada na teoria económica, segundo a qual o valor do produto final terá de ser superior à soma do valor dispendido, parcelarmente, em cada um dos recursos usados na respetiva produção, o mesmo investigador critica a generalizada ausência de valor acrescentado na informação noticiosa, o que a torna, por seu turno e aos seus olhos, igualmente pouco diferenciada. Em síntese, aquilo que Robert Picard afirma é que a generalidade dos jornalistas dispõe das mesmas competências e tem os mesmos ângulos de abordagem, recorre às mesmas fontes, faz perguntas idênticas e escreve textos relativamente semelhantes. Daí, sustentar que este trabalho pouco diferenciado e facilmente substituível explica os salários baixos da média dos jornalistas, em contraste com os pagamentos mais chorudos feitos aos colunistas, cartoonistas e jornalistas especializados.

Em Robert Picard existem preferencialmente consumidores em vez de cidadãos e a informação jornalística é vista e analisada segundo a satisfação de três benefícios: funcional, emocional e identitário. Ora, quando tais benefícios podem e passam a ser satisfeitos através e junto de outros meios e fontes, isso significa que o produtor inicial deixa, como sucedeu durante o último século, de 
ter o monopólio na distribuição da informação e de ter esse mesmo exclusivo no acesso a fontes autorizadas e ao espaço público mediatizado.

"A emergência de canais noticiosos durante as 24 horas, os talk-shows e a internet oferecem às pessoas a possibilidade, nunca antes experimentada, de seguir acontecimentos em tempo real, receber informação diretamente de entidades conhecedoras e autorizadas e, ainda, de interagir com as fontes de informação através de uma multiplicidade de formas e plataformas nunca antes tornadas possível"127, realça ainda Robert Picard, para quem os novos meios de comunicação reduzem o valor do trabalho anteriormente desempenhado pelos jornalistas que eram os únicos que tinham a possibilidade de aceder e relatar os acontecimentos, assim como detinham a exclusividade no acesso às fontes e ao conhecimento. "O primeiro valor económico do jornalismo - observa o mesmo autor - reside não no seu conhecimento próprio, mas na capacidade de distribuição do conhecimento dos outros"128, vantagem essa que se esbate ou desaparece, a partir do momento em que existem outras opções.

Donde, se agora existem organizações e mecanismos alternativos capazes de executar as mesmas tarefas e responder às mesmas solicitações e expectativas do público ou, dito de outra maneira, se este pode aceder e comunicar sem necessitar da intermediação de qualquer instância jornalística, isso traduz, à luz do pensamento de Robert Picard, uma menor dependência dos consumidores face aos media noticiosos e uma fragilidade crescente destes e dos seus profissionais no quadro da respectiva atuação.

Percebe-se porquê. Afinal de contas, como chega, hoje, a informação a uma parte considerável dos cidadãos? Pois bem, deixando de lado qualquer análise sobre a qualidade em que se processam os novos circuitos informativos, aceitemos como certa a ideia - facilmente constatável, de resto - de que a uma parte cada vez maior dos cidadãos, a informação chega-lhe, sobretudo, através da net e das suas múltiplas redes sociais, em mensagens curtas e reduzidas. Significa isso que, gradualmente, estamos a habituar-nos, como cidadãos, a tomar como representações da realidade as micronarrativas dessa mesma realidade, o que torna a informação e a apropriação da respetiva realidade ainda mais simplista.

127 "Why journalists deserve low paid", Conferência apresentada por Robert Picard, no Reuters Institute for the Study of Journalism, University of Oxford, 6/05/2009, p. 4

128 Idem, p. 3 
Motivo este, dir-se-á, que reforça a ideia de necessidade de uma informação mais completa feita por jornalistas, segundo os critérios e os princípios da profissão.

É sabido que o jornalismo procura transmitir de forma simples e acessível o que é complexo. O risco atual reside em transmitir apressadamente e de forma simplista apenas o que é simples. E o risco é real e propaga-se à velocidade da luz. De uma forma tendencialmente crescente, como sustenta Adriano Duarte Rodrigues, "são as redes mediáticas que dimensionam a comunicação em termos universais. Quebram, no espaço e no tempo, as fronteiras convencionais; mobilizam e mantêm disponíveis conteúdos múltiplos, colocados ao acesso de contextos virtuais muito diversificados. São estas redes mediáticas que, em virtude das suas potencialidades, flexibilidade e performatividade — acrescenta o mesmo investigador — dão a exata dimensão do espaço público contemporâneo: já não um espaço essencialmente topológico e físico, mas, cada vez mais, um espaço simbólico e reticular" (Rodrigues, 2001: 123), em circulação permanente nas autoestradas da informação, as quais "encarnam a ilusão de um tempo único da informação", como se a "ideologia técnica” pudesse, por si só, cumprir essa utopia do tempo único mundial, por esbatimento dos "tempos históricos locais" (Wolton, 1999:291).

No entanto, como nos alerta Dominique Wolton, se é verdade que a sociedade imperial da tecnologia pode permitir-nos seguir e ver tudo, isso não significa, como ele próprio também assinala, que se possa compreender tudo ${ }^{129}$. Crítico daquilo a que designa por "ideologia técnica", Wolton defende que toda a comunicação é uma relação de forças, sublinhando, a este respeito, que o horizonte de qualquer comunicação está na relação com o outro.

Daí colocar o fator humano no centro e razão de ser do processo comunicativo $^{130}$, o qual, em seu entender, comporta três tipos de comunicação intersubjetiva ou humana, mediática e a internet - aceitando que todos eles desempenham um papel próprio e que, por isso mesmo, não faz sentido escolher

129 A reflexão em torno dos problemas e dos desafios que se colocam à comunicação, colocada perante os avanços tecnológicos e as desigualdades que eles acentuam, constitui um elemento essencial do pensamento do autor. Resultado de 20 anos de pesquisa e investigação, Dominique Wolton critica neste seu livro - Pensar a comunicação (1999) - obra central no seu vasto trabalho, o domínio da "ideologia técnica" e aponta para a necessidade de uma redescoberta e reforço das identidades.

130 Em seu entender, "qualquer teoria da comunicação que não enuncie formalmente a visão da sociedade que lhe está associada é caduca", na medida em que "não existe teoria da comunicação sem uma teoria da sociedade", (Wolton, 1999: 41) 
ou prescindir de um deles, mas antes conjugar ou concertar as três formas de comunicação numa espécie de conciliação estratégica, em que o significado e a narrativa da comunicação apresentam marcas culturais e ideológicas que escapam à gramática exclusivamente tecnicista do dispositivo comunicacional.

Em Pensar a comunicação, Wolton sustenta, aliás, que a verdade não está no ato de mostrar tudo e dizer tudo, razão pela qual propõe o reforço do papel do jornalista como intermediário generalista entre o espetáculo do mundo e o público, mesmo sabendo que a informação não se reduz à narrativa do acontecimento. Isto, porque a lógica comunicacional, de que a vertente noticiosa é parte integrante, mas não exclusiva, é hoje dominada pela cultura da espetacularidade, onde a sobremediatização dos acontecimentos e a dificuldade em os apresentar em perspetiva, constituem sinais marcantes e preocupantes do exercício atual da informação noticiosa.

"De repente, desliza-se facilmente da ideia de liberdade devida à ausência de intermediários, para a ideologia da imediatez. Tudo é público e imediato” (Wolton, 1999: 183). E assim sendo, a "aventura já não é o acesso ao acontecimento mas, sim, a sua compreensão. Demasiada informação mata os factos e a sua compreensão. Este é o resultado paradoxal da vitória do paradigma da informação: o acontecimento satura a informação. Ou melhor, a informação, em vez de ser a escolha entre diversos acontecimentos, torna-se, simplesmente, a sua soma" (Wolton, 1999: 225). Estaremos, à luz deste raciocínio, a assistir à morte da notícia e ao esgar dos critérios de noticiabilidade?

$\mathrm{Na} 4^{\mathrm{a}}$ Conferência Internacional de Jornalismo realizada em novembro de 2010, em Estrasburgo, Philippe Lefait, do canal televisivo France 2, na linha das palavras de Wolton, lançou o seguinte grito de alarme: "o excesso de informação mata as notícias"131. Queria ele dizer com isso que o jornalismo tem de recuperar os seus fundamentos, realçando que se "antigamente os cidadãos eram questionados pelos jornalistas, agora lidamos com um público consumidor e jornalistas vendedores"132.

Jérome Bouvier, presidente deste encontro internacional que junta atores da informação e públicos para debaterem a qualidade da informação, considera que

\footnotetext{
131 "O tempo dos slow media", in Courrier International, n 179, Janeiro 2011, p. 73

132 Idem
} 
a possibilidade de a profissão de jornalista, como hoje a conhecemos, poder vir a desaparecer dentro de uma década está longe de ser um risco sem sentido.

Como ele, o movimento slow media, criado em janeiro de 2010 na Alemanha, sustenta que o jornalismo "é uma profissão que precisa de tempo", quando o seu exercício atual se resume em correr mais depressa que o respectivo concorrente. Tal "vertigem de imediatismo", para usar a expressão de Bouvier, está a arruinar a profissão, uma vez que se incentiva a velocidade e a profusão de notícias, em detrimento da sua seleção cuidada e de um tratamento qualificado da informação.

O coro das vozes desencantadas sucede-se. Patrick de Saint-Exupéry, chefe de redação e cofundador da revista francesa $X X I^{133}$, publicação trimestral vocacionada para a grande reportagem e que sobrevive graças aos 52 mil exemplares que vende, dado que não aceita publicidade nas suas páginas, sublinha que a sua equipa, quando trabalha, "tem sempre presente que está a escrever para alguém e que esse alguém é um leitor, não é um destino"134 .

Até que ponto é que esta revista, rentável e com as contas equilibradas, não responde à ideia de diferenciação e de valor acrescentado de que Picard nos falava há pouco?

É interessante observar como perante o exercício de uma profissão e de uma atividade económica, em clara derrapagem e em inquestionável fase de transformação, o pensamento predominantemente editorial se aproxima, no plano das suas opções estratégicas, do olhar economicista.

Robert Picard entende que a sobrevivência do jornalismo está na sua capacidade de inovar e criar novas formas de aproximação, processamento e distribuição de informação, de modo a disponibilizar conteúdos e serviços a que os seus públicos não possam aceder de outra maneira. E se assim for, esses mesmos públicos, que este investigador classifica de consumidores, estarão dispostos a pagar um preço razoável pela informação em causa. Para que isso aconteça, o mesmo autor alerta para a importância decisiva das lideranças no quadro das decisões estratégicas das respetivas organizações, porquanto elas têm, em seu entender, de olhar para os interesses amplos e diferenciados dos seus stakeholders,

133 A 24 de Março de 2011, a mesma equipa lançou a revista semestral 6 Mois, inteiramente dedicada à foto-reportagem. Como a XxI, não aceita publicidade e também não se encontra à venda nos quiosques - apenas se compra em livrarias ou em assinatura pela internet.

134 "O tempo dos slow media", in Courrier International, $\mathrm{n}^{\circ} 179$, Janeiro 2011, p. 73 
numa perspetiva de superação dos meros objetivos perseguidos pelos respetivos sharebolders, a fim de conseguirem encontrar formas de incorporar valor suficiente no jornalismo, para que os consumidores o suportem financeiramente (Picard, 2010). Quer isto dizer, ainda na linha de pensamento do mesmo autor, que o jornalismo tem de ser capaz de inovar e de encontrar fórmulas novas e mais exigentes de prestar a informação, embora admita que o modelo de negócio que possa suportar uma opção desta natureza não é fácil de encontrar e de pôr em prática.

A esta mesma conclusão chegaram, de resto, recentemente, em Madrid, os diretores de Le Monde, El Pais The Guardian, The New York Times e Der Spiegel, durante um debate sobre "O futuro do jornalismo" ${ }^{35}$, realizado no museu Reina Sofia.

O pretexto do debate foi a publicação, por aqueles órgãos de comunicação social, dos telegramas disponibilizados pela Wikileaks, mas a ocasião foi aproveitada para discutir o novo cenário informativo e o papel e a relação do jornalismo com os cidadãos, em especial através do on-line, visto ser esse o meio em que todos os intervenientes apostam fortemente e no qual, acreditam, está o futuro. Divide-os, no entanto, uma questão central: como pagar um jornalismo de qualidade num quadro comunicacional predominantemente gratuito? Georg Mascolo, diretor da revista alemã Der Spiegel, hesita, como os outros, no modelo de negócio a seguir. Contudo, arrancou a maior ovação da tarde quando disse que se recusava a aceitar que uma revista fosse mais barata que um café no Starbucks, porque os custos de uma redação qualificada e o consequente exercício de uma informação exigente têm preços elevados e alguém terá de os suportar.

Esta representa, a meu ver, a questão central da discussão em torno da necessidade de existência de um jornalismo independente, credível e qualificado nos nossos dias, numa altura em que o desenvolvimento do google news, com o seu sistema de acesso e transmissão de notícias, constitui um exemplo notório e notável da massificação informativa a custo zero. Confrontados com uma tendência crescente do acesso gratuito à informação, esta apenas pode ambicionar ter um

135 O encontro foi realizado a 27 de fevereiro de 2010 e foi aproveitado para cada um dos diretores manifestar as suas incertezas quanto às opções de ordem económica a seguir no que toca às edições eletrónicas. Todos concordaram que os respetivos títulos em papel estarão condenados, a prazo, assim como não têm dúvidas que o futuro da informação está no online. 
preço se os seus destinatários estiverem dispostos a pagar por ela, porque a consideram exclusiva, relevante ou útil à resposta das suas necessidades profissionais ou de cidadania.

Colocados perante este dilema que é, ao mesmo tempo, o maior desafio do jornalismo atual e da sua forma de exercício, Robert Picard atira a primeira pedra com a mais profunda das suas convicções: o uso das novas tecnologias, a atenção permanente às redes sociais, a pesquisa de websites especializados, a procura de inspiração para as suas estórias em weblogs e o exercício do chamado jornalismo colaborativo com as audiências, apesar dos aspetos positivos e vantagens que apresenta tal prática, ela, só por si, não acrescenta valor à informação jornalística. Por uma razão simples, em seu entender: a maior parte dos interessados naquelas matérias utilizam, na sua busca e discussão, os mesmos recursos, competências e instrumentos dos jornalistas.

Esta procura ansiosa e permanente por novos conteúdos noticiosos, com o objetivo de os editar o mais depressa possível nas diversas plataformas que cada órgão de comunicação social administra atualmente, tem vindo a conduzir, por seu lado, à afirmação do conceito de marca informativa, em detrimento do velho título que cada media orgulhosamente ostentava no cabeçalho do respectivo jornal. "A imprensa que era artesanal — refere Patrick de Saint-Exupéry — tornou-se numa indústria quase mecânica", ao mesmo tempo que "aos jornalistas foi entregue o papel de técnicos de informação, em detrimento da legitimidade da sua função primordial: dar notícias"136.

É justamente dentro deste quadro de referências que faz sentido atender às palavras de Robert Picard, quando ele aponta para a necessidade de uma nova forma de organização e cooperação entre empresas, mas cuja renovação deve incluir os jornalistas. Nesse sentido, jornalistas e administradores devem promover uma estreita colaboração conjunta e criar um quadro de relacionamento social que possibilite a concretização dos objetivos que são comuns. Paralelamente, sublinha Picard, "os jornalistas têm de adquirir competências ao nível da inovação e do empreendedorismo, de modo a que eles possam também liderar esse processo de mudança, em vez de se limitarem a reagir a ele"137. Caso contrário,

136 "O tempo dos slow media", in Courrier International, n ${ }^{\circ}$ 179, janeiro, 2011

137 "Why journalists deserve low paid", Conferência apresentada por Robert Picard, no Reuters Institute for the Study of Journalism, University of Oxford, 6/05/2009, p. 6 
"se os jornalistas não criarem mais valor no trabalho que realizam e se não se envolverem mais intensamente nos destinos das respetivas empresas — sustenta o mesmo autor — os seus salários serão progressivamente diminuídos, ao mesmo tempo que as suas empresas irão definhar e morrer"138. Para Robert Picard, o jornalismo e as respetivas empresas enfrentam um momento decisivo da sua existência, pelo que uns e outros têm de entender o novo quadro competitivo em que se movimentam e, nessa perspetiva, serem capazes de encontrar as soluções adequadas às atuais circunstâncias (Picard, 2010).

Percebe-se porquê. O jornal "enquanto empresa, local de trabalho e modelo jornalístico baseado apenas na escrita e na fotografia terminou ou, melhor, não terminou ainda, mas encontra-se num processo de mutação, que nos fará olhar para este momento atual como um início de rutura" ${ }^{139}$ Assim sendo, é a própria cultura organizacional e a gestão de recursos humanos que estão em causa. "O desafio é enorme — sustenta Gustavo Cardoso — porque implica que as empresas adotem ciclos de produção adaptados às dietas de media e dos consumidores" e, sobretudo, exige uma nova cultura de gestão, em que a empresa interiorize a prática de atitudes criativas "dirigidas para a conquista de leitores", recusando "soluções únicas, estanques, permanentes". Vendo bem, trata-se, no fundo, de "aprender a inovar nos modelos e não apenas nos conteúdos, recusando também a ideia de um produto final único", enquanto representante de um "pensamento monopolizante". ${ }^{140}$

Da mesma maneira que não há um público mas muitos e diversificados públicos que querem coisas diferentes e a diferentes horas do dia, isso quer dizer que o jornalismo terá de procurar e dar notícias diferentes. Tal como observámos no pensamento de Robert Picard, também Gustavo Cardoso entende que tem de haver uma notória diferenciação e valor acrescentado na informação a veicular, pela simples razão, sublinha, de que o "mediado já chega por via de diferentes fontes, profissionais ou outras, tanto ao jornalista como ao público. O que significa que, para haver diferença, tem de haver mais tempo no terreno, tem de haver

\footnotetext{
138 Idem, p. 6

139 "Da comunicação de massa para a comunicação em rede", in Media, Redes e Comunicação, (Coord) Gustavo Cardoso, Francisco R. Cádima, Luís L. Cardoso, Quimera, 2009, Lisboa, p. 44

140 Idem, pp. 44-45
} 
fontes face-a-face, estar na rua, ir onde a redação não chega, gravar, escrever a partir dos locais dos acontecimentos". ${ }^{141}$

Aquilo que Gustavo Cardoso aqui nos propõe é, no essencial, o regresso do jornalismo ao seu habitat, numa altura em que ele é visto como uma peça de uma sofisticada engrenagem, no interior da qual o jornalista é uma espécie de operador de computador, a quem é exigida uma produção diária de textos que é impossível elaborar segundo o estado da arte da profissão.

A atual era do ciclo noticioso de 24 horas implica que as redações ocupem o seu tempo em busca de novos dados para acrescentar às informações existentes. Sucede, no entanto, que essa procura não traz, em regra, novos dados nem verifica os que foram veiculados. Limita-se a apresentar mais interpretações, porque a cultura jornalística dominante, regra geral, tem vindo a enfraquecer e a desviar a metodologia da verificação que constitui o tronco central do seu trabalho, para o chamado jornalismo de citação.

Tal modelo organizacional e da ação jornalística, como Tom Rosenstiel e Bill Kovach demonstram na sua obra, Os elementos do jornalismo, comporta sérios riscos e, sobretudo, está a retirar os jornalistas do epicentro dos acontecimentos, conduzindo, com essa atitude, ao empobrecimento da própria informação. Os mesmos autores consideram, aliás, que "à medida que os jornalistas passam mais tempo a tentar sintetizar o interminável fluxo de dados que lhes chegam através dos novos portais de informação, correm o risco de se tornarem mais passivos, mais receptores do que colectores de informação" (Kovach e Rosenstiel, 2004:80)

Sem tempo para pensar nem confirmar e muito menos para aprofundar e colocar em perspetiva os textos que escreve, o jornalista limita-se a produzir em série, estando, assim, à mercê das fontes mais bem apetrechadas e que, sabedoras dos constrangimentos organizacionais das empresas jornalísticas, conseguem dominar e influenciar a agenda informativa.

O cenário atual é de grande concorrência e a informação é permanente e instantânea, ao ponto, como diz Debray, referindo-se à ideia de prescrição das notícias, de "reconduzir Sísifo, em cada manhã, ao sopé da montanha" (Debray, 1994: 31).

$141 \quad$ Idem, pp. $45-46$ 
A atualidade, por seu turno, é comandada pelo sensacionalismo e pela dimensão espetacular da informação, ao ponto de ter deslocado a própria política do estrito domínio do confronto e da discussão ideológica para o terreno movediço do fait-divers e do escândalo. "A regra dos duelistas de outrora, a do primeiro sangue" ${ }^{142}$, segundo a expressão de Jean Lacouture, é também a do jornalismo de hoje, cada vez mais atento e preocupado com a construção de uma realidade parcialmente considerada, onde, "tudo o que era diretamente vivido se afastou numa representação", como se as imagens em que nos olhamos e vemos "o espetáculo como inversão concreta da vida" correspondessem à ideia de "pseudomundo à parte", de que nos fala Guy Debord, em "A sociedade do espetáculo" (Debord, 1991: 9).

Perante este cenário, no qual crescem todos os dias os apelos e encorajamentos ao papel do cidadão-jornalista (seja isto o que for), e onde a influência das agências de comunicação e gabinetes de assessoria dispõem hoje de meios incomparavelmente maiores que a generalidade das redações, importa perguntar para que serve o jornalismo? Por outras palavras: qual a sua função nas atuais sociedades, numa altura em que qualquer empresa ou instituição pode, através das redes digitais, comunicar diretamente com os seus potenciais destinatários, sem necessitar da intermediação jornalística?

Na sua génese, o jornalismo comporta os conceitos de independência, verdade, vigilância, interesse público, sem que todas estas características coexistam em simultâneo no mesmo título. Mas elas são o seu ADN, a sua marca d’água. Se assim não for, como podem as sociedades democráticas sobreviver sem uma informação livre e independente?

Esta é uma questão central, por vezes muito ignorada, justamente porque ela não faz parte das preocupações do chamado jornalismo de mercado ${ }^{143}$ que constitui hoje o discurso dominante no espaço mediático. Desligado da ideia de responsabilidade cívica, essa forma de exercer o jornalismo, amiga do conceito de globalidade e defensora da homogeneização dos públicos, professa

142 Lacouture, Jean, "A História imediata", in A Nova História (dirigida por Jacques Le Goff, Roger Chartier, Jacques revel), Almedina, 1990, p. 334

143 Esta ideia é desenvolvida, entre outros, pelo sociólogo Pierre Bourdieu, para quem o campo jornalístico estrutura-se segundo o "polo comercial" e o "polo intelectual". No primeiro, os jornalistas determinam a sua atitude em função do mercado, da audiência; no segundo, atendem à qualidade do produto jornalístico e aos valores da deontologia profissional. 
essencialmente as virtudes do alargamento do mercado, numa perspectiva de aproveitamento das múltiplas plataformas de comunicação disponíveis.

Paralelamente, a informação deixou de ser um exclusivo dos órgãos de comunicação social, para se tornar um conteúdo que as grandes plataformas, sobretudo digitais, colocam gratuitamente à disposição de qualquer pessoa. O mesmo sucede com o fenómeno dos jornais gratuitos que hoje tomou conta das grandes cidades. A ideia subjacente é idêntica: dar de forma rápida, sumária e a custo zero para o destinatário um conjunto de notícias produzidas segundo o sistema de low cost.

Ora, não é possível nem desejável entender este processo como algo que apenas diz respeito aos jornalistas e se esgota na sua função, sem atender ao papel ativo que, neste contexto, nos deve caber a nós, cidadãos.

Se a informação, como já foi dito, visa fornecer instrumentos e dados para os cidadãos melhor decidirem sobre os destinos das suas comunidades e países, mas se esses mesmos cidadãos preferem consumir ou prestar mais atenção a temáticas centradas em escândalos ou na vida pessoal de figuras públicas, isso significa que há um imenso trabalho de fundo para fazer e cujo alvo, entendamo-nos, não se circunscreve apenas às pessoas com menores habilitações académicas.

A grande dificuldade é que o jornalismo de qualidade e de referência, que hoje enfrenta problemas sérios em quase todas as latitudes, não pode esperar tanto tempo. E como também não vive isolado no espaço mediático, os últimos anos mostram-nos uma crescente contaminação dos órgãos de referência por temáticas e espaços editoriais que até há pouco tempo eram do domínio exclusivo da imprensa popular. Este, portanto, e aqui apresentado de modo muito resumido, o enorme dilema do jornalismo atual: mercado desregulado, competição desenfreada pelos públicos e audiências, predomínio do espetáculo e do entretenimento, imediatismo, afirmação dos grandes grupos, aposta na inexperiência e baixos salários, transferência dos públicos para o on-line, sem que tal mudança equilibre, para já, a crise da imprensa e a sua perda dos proventos comerciais.

Tudo nos diz, portanto, que o jornalismo como o entendemos e vimos durante décadas a fio está a acabar. Não direi a sua função, que esta ainda não encontrou um substituto credível e à sua altura. Refiro-me ao modo como ele hoje é entendido na generalidade dos seus contextos organizacionais e também como é praticado e às escolhas das temáticas a que ele dá mais atenção e espaço, 
num contexto tecnológico completamente novo e cujas potencialidades alteraram também a forma de exercício do jornalismo.

Mas se a tecnologia e as técnicas de comunicação mudaram, os princípios do jornalismo mantêm-se inalterados, não obstante as transformações que a profissão está a enfrentar. Claro que a fragilização das redações, acompanhada por uma estratégia de comunicação assente em linguagens e critérios alheios ao jornalismo tornam este mais fraco e dependente.

O jornalismo, com se sabe, tem um valor instrumental, cuja relevância é exterior a si próprio. Isto é, o jornalismo não é importante em si mesmo, da mesma maneira que o seu exercício não é um discurso sobre si próprio; a sua importância comporta uma dimensão instrumental, no sentido em que a sua prática visa o esclarecimento do público, apoiar a interação social, assumir-se como um elemento facilitador e de dinamização do jogo democrático.

Resta saber, portanto, à luz desta observação, qual o grau de responsabilidade que o cidadão deve ter na defesa e preservação de um jornalismo de qualidade, dado que enquanto recetor e nas palavras de Mauro Wolf "é parte ativa do processo de comunicação"144. Hugo Aznar pergunta se "pode o público continuar a ser considerado como alheio ao processo de comunicação e a sua participação nos media como uma intromissão?", para defender que tal "participação não só constitui um direito mas também uma obrigação" (Aznar, 2005:189).

Para este professor de Filosofia e Jornalismo, da Universidade de Valência, o público, "na medida em que pode escolher e agir, por pouco que seja, também tem uma parte de responsabilidade na tarefa de melhorar a comunicação, de se esforçar para que ela se ajuste mais aos seus valores e princípios éticos" (Aznar, 2005: 189).

Nesta linha de pensamento, entende-se que "não é só pertinente falar de uma ética do jornalista e de uma ética da empresa comunicativa, mas também de uma ética do público, uma ética dos utilizadores da comunicação, dos recetores ou da audiência" (Aznar, 2005:189). O consumo dos media "deve ser, assim, visto”, segundo as palavras de Hamelink, que chega até a formular um decálogo dos deveres do público, "como uma atividade social que implica

144 Wolf, Mauro, La investigación de la comunicación de masas. Críticas y perspectivas, Barcelona, Paidós, 1996, p. 79 
decisões morais e, portanto, a consequente assunção da responsabilidade derivada dessas decisões"145.

Esta ideia de responsabilidade cultural coletiva que se aproxima do conceito de responsabilidade ecológica, no sentido em que todos somos responsáveis por cuidar do ambiente, remete um pouco para a expressão do escritor Henri Michaux quando ele chama à sua cabeça "as minhas propriedades", na perspetiva de que é nesse território individual e intransmissível que se aloja toda a gama de informação que recebemos e captamos.

Daí, que a qualidade da informação que é dada aos cidadãos é tão importante como a existência de um clima de liberdade e pluralidade para a veicular. Não basta poder publicar e dizer o que se quer - é preciso ter as condições para perceber, aprofundar e verificar a informação que se fornece e observar a sua qualidade. Caso contrário continuaremos a falar de liberdade de informação, mas no plano formal, das aparências, e não da sua substância.

E se assim for, não é apenas a liberdade de informação que estará em causa — é a democracia que estará em risco. Ora, não "deveria haver em cada um de nós - como nos desafia Michael Sandel, professor de Filosofia em Harvard - um voz importuna que perguntasse permanentemente: será que alguém vai também comprar a democracia?"146.

A existência de uma boa informação nas sociedades democráticas e abertas em que habitamos é um bem público de primeira necessidade como a eletricidade ou a água - é impossível viver sem elas. Donde, será normal que a informação jornalística qualificada, exigente e diferenciadora tenha também o seu custo, valor e relevância.

O escritor Gonçalo M. Tavares, que foi diretor por um dia do Diário de Notícias, na edição do $147^{\circ}$ aniversário do jornal, escreveu na ocasião a mesma coisa com as palavras admiráveis com que termino este texto: "um médico responsável, um médico de seres humanos e não um médico de órgãos que ainda estão vivos, logo a seguir à questão: o que é que come? deveria perguntar ao seu paciente: o

145 Hamelink, Cees J. "Ethics for media users", European Journal of Communication, Vol. X, n ${ }^{\circ}$ 4, p. 504, citado por Hugo Aznar na obra Comunicação responsável. A auto-regulação dos media, Porto Editora, 2005, p. 189

146 A frase foi primeiramente citada por Thomas Friedman, num texto intitulado "Corporations on Steroids", publicado no The New York Times de 4/02/2000. Bill Kovach e Tom Rosenstiel recuperam a expressão de Michael Sandon e inserem-na no livro, Os elementos do jornalismo. 
que é que lê? e que imagens é que vê habitualmente? o médico que se preocupa com a saúde do seu paciente, tal como aconselha alimentos e hábitos, poderia aconselhar filmes, livros, fotografias, concertos e artigos de jornal”147.

147 Editorial do $D N, 29 / 12 / 2010$, "Das leituras e da medicina", p. 8 


\section{BIBLIOGRAFIA}

AZNAR, Hugo, Comunicação responsável. A auto-regulação dos media, Porto Editora, 2005.

CARDOSO, Gustavo, "Da comunicaçãoo de massa para a comunicação em rede", in Media, redes e comunicação. Futuros presentes, Coord: Cardoso, Gustavo; Cádima, Francisco Rui; Cardoso, Luís Landerset, Quimera, 2009.

DEBORD, Guy, A sociedade do espetáculo, Mobilis in mobili, Lisboa, 1991

DEBRAY, Régis, O Estado sedutor. As revoluções midiológicas do poder, Editora Vozes, Petrópolis, 1994.

KOVACH, Bill; ROSENSTIEL, Tom, Os elementos do jornalismo, Porto Editora, 2004.

LACOUTURE, Jean, "A História imediata", in A Nova História (dirigida por Jacques Le Goff, Roger Chartier, Jacques Revel), Almedina, 1990.

LÓPEZ, Gabriel Galdón, Desinformação e os limites da informação, Folhas \& Letras, Lisboa, 2003.

PICARD, Robert, Value creation and the future of news organizations: why and how journalism must change to remain relevant in the twenty-first century, Media XXI, Lisboa, 2010.

RODRIGUES, Adriano Duarte, Estratégias de comunicação, Presença, 2001.

SERRANO, Pascual, Desinformación. Cómo los médios ocultan el mundo, Ediciones Península, Barcelona, 2009.

Wolton, Dominique, Pensar a comunicação, Difel, Lisboa, 1999.

\section{Conferência}

Why journalists deserve low paid, Robert Picard, Conferência apresentada no Reuters Institute for the Study of Journalism, University of Oxford, 6 de Maio de 2009.

\section{Jornais}

Courrier International, no 179, Janeiro, 2011-04-21

Diário de Notícias, 29 Dezembro de 2010

El País, 24 e 25 de Fevereiro de 2010.

Público, 25 de Fevereiro, 2010

Expresso, 26 de Fevereiro de 2010. 